\title{
RECALQUE E REPRESSÃO: UMA DISCUSSÃO TEÓRICA ILUSTRADA POR UM FILME
}

Maria Lucia de Souza Campos Paiva

Doutora em Psicologia Clínica pelo Instituto de Psicologia da Universidade de São Paulo. Professora e supervisora do curso de Psicologia do CCBS da Universidade Presbiteriana Mackenzie (São Paulo).

\section{Resumo}

As primeiras traduções para o português da obra freudiana acabaram apresentando problemas, pois não foram feitas diretamente do alemão. Mais de cem anos depois do início da psicanálise, ainda há inúmeras discussões a respeito da metapsicologia freudiana e a dificuldade em se chegar a um consenso na tradução de alguns conceitos. O presente artigo retoma os conceitos freudianos de recalque originário, recalque e repressão. Para discutir tais conceitos, utilizou-se um filme co-produzido por alemães/argentinos, cujo nome original é Das lied in mir, lançado em 2011 e dirigido por Florian Micoud Cossen. Por meio da película, estes conceitos freudianos são analisados e é discutida a diferenciação dos conceitos: recalque e repressão, mostrando a importância da tradução precisa dos mesmos.

Palavras-chave: psicanálise, repressão (mecanismo de defesa), inconsciente (fator de personalidade)

\section{SUPPRESSION AND REPRESSION: A THEORETICAL DISCUSSION ILLUSTRATED BY A MOVIE}

\begin{abstract}
The first translations of Freud's work into Portuguese have presented problems because they were not translated from the German language. More than a hundred years after the beginning of Psychoanalysis, there are still many discussions on Freud's metapsychology and a considerable difficulty in obtaining a consensus on the translation of some concepts. This paper refers back to Freud's concepts of primal repression, repression and suppression. In order to discuss such concepts, we have made use of a film, co-produced by Germans and Argentineans, which is named "The Song in me" (Das Lied in mir), released to the public in 2011 and directed by Florian Micoud Cossen. Through this motion picture, the following of Freud's concepts are analyzed, and the differentiation between them is discussed: suppression and repression, as well as the importance of their precise translation.
\end{abstract}

Keywords: psychoanalysis, repression (defense mechanism), unconscious (personality factor) 


\title{
SUPRESIÓN Y REPRESIÓN: UNA DISCUSIÓN CONCEPTUAL BASADA EN LA PELÍ́CULA
}

\begin{abstract}
Resumen
Las primeras traducciones de la obra de Freud al portugués han presentado problemas porque no se han traducido directamente de la lengua alemana. Más de cien años después del comienzo de la psicoanálisis, todavia hay muchas discusiones sobre la metapsicologia freudiana y una dificultad considerable en la obtención de un consenso sobre la traducción de algunos conceptos. Este documento vuelve a los conceptos freudianos de represión originaria, represión y supresión. Para discutir estos conceptos, se ha hecho uso de una película coproducida por alemanes y argentinos, que se Ilama "Das Lied in mir" ("El día en que yo no nació"), lanzada en 2011 y dirigida por Florian Micoud Cossen. A través de esta película, los dos conceptos de Freud - supresión y represión - se analizan y la diferenciación entre ellos se discute, así como la importancia de su traducción precisa.
\end{abstract}

Palabras clave: psicoanálisis, represión, inconsciente (factor de la personalidad)

Essa ausência bem suportada, não é outra coisa senão o esquecimento.

Sou momentaneamente infiel.

É a condição da minha sobrevivência;

se eu não esquecesse, morreria.

Werther em Fragmentos de um Discurso Amoroso.

Roland Barthes (1977)

\section{INTRODUÇÃO}

A tradução da obra freudiana tem causado muitas discussões teóricas, desde as primeiras traduções que foram feitas diretamente do inglês para o português. Atualmente, mais de cem anos depois, aparecem as primeiras traduções feitas diretamente do alemão. Entretanto, no meio psicanalítico, a discussão a respeito do emprego de algumas palavras ainda causa estranheza e discórdia entre alguns psicanalistas e contentamento entre outros. No intuito de contribuir na interlocução do emprego de alguns termos importantes na metapsicologia freudiana, o presente artigo tem como objetivo diferenciar o significado de recalcamento originário, recalque e repressão. Para enriquecer e ilustrar tais conceitos, optou-se por utilizar um filme como pano de fundo. No início de trabalho, é narrado sucintamente o enredo do filme e, em seguida, é apresentado o conceito de recalcamento originário e repressão. Posteriormente, é abordado o conceito de alucinação negativa, enquanto um mecanismo de defesa que corrobora com a sustentação da repressão. Por fim, algumas considerações finais são apontadas. 


\section{"Das Lied in mir"}

"Das Lied in mir" é o título original dado ao filme de produção alemã/argentina e dirigido por Florian Micoud Cossen. O elenco é formado por Jessica Schwarz, Michael Gwisdek e Rafael Ferro. O filme, que foi vencedor do Prêmio da Crítica e do Público no Festival de Montreal e considerado o melhor filme no Festival de Zurich, traz a história de uma mulher em busca de seu verdadeiro passado. No Brasil, o filme chegou aos cinemas com o título: "O dia em que eu não nasci".

Maria (Jessica Schwarz), uma nadadora alemã, em uma breve passagem por Buenos Aires, a caminho do Chile, ainda no aeroporto aguardando seu vôo, ouve uma canção de ninar que uma mulher canta para uma criança que está em seu colo. Ao ouvi-la, começa a cantarolar em castelhano, língua que imaginava que desconhecia. Mobilizada pela situação, Maria cai em um pranto forte, sem muito saber o que se passa com ela. A partir de então, sente uma estranha fascinação por aquele lugar e passa a se interessar pela capital argentina e decide permanecer mais tempo por lá. Ao caminhar pela cidade, vê um Topo Gigio em uma vitrine de uma loja. Resolve comprá-lo, pois o boneco lhe parece muito conhecido. Telefona para seu pai para contar a experiência inusitada que tivera e, alguns dias depois, Maria é surpreendida pela visita de seu pai (Michael Gwisdek). Ao questioná-lo sobre o boneco, se tivera um igual na infância, seu pai diz que não se lembra. Maria não se contenta com a resposta e pressiona-o para contar o que ocorreu em seu passado. Seu pai revela que, na verdade, ela viveu seus primeiros anos de vida na Argentina, antes de ser adotada e levada para a Alemanha. Maria desconhecia, conscientemente, essa parte de sua história. A partir daí, Maria inicia a busca pela família biológica com a ajuda de seu pai. Ela descobre que seus pais biológicos foram sequestrados na época da ditadura argentina. Como ninguém busca Maria na escola, sua professora, que gostava muito dela, resolve levá-la para casa e "adota" a menina de modo clandestino. A verdade sobre o processo de sua "adoção" é descoberta por Maria por meio de seus tios argentinos.

O filme todo passa a girar em torno da aproximação de Maria com a sua família biológica e a revelação de sua história familiar. Em determinado momento, Maria confronta seu pai, questionando por que ele não havia lhe contado que seus tios estiveram procurando por ela, na casa de seus pais adotivos, depois que seus pais biológicos desapareceram. Na época, seus pais 
adotivos disseram a seus tios que não sabiam do paradeiro de Maria, sendo que ela já estava morando com eles. Nesta cena, o pai adotivo nega que o fato tenha ocorrido e, em seguida, diz que não se lembra do que aconteceu na época. Maria, indignada com tudo que estava sendo descoberto por ela, relembra que sua mãe adotiva costumava Ihe contar sobre a gravidez e o início de sua vida.

\section{A teoria Freudiana}

O trauma, a adoção clandestina, vivido por Maria e sua família, torna-se um segredo, algo da ordem do não-dito, do impensável. Maria recalca a história vivida com seus pais biológicos e, seus novos pais negam o que haviam feito: tirado Maria de sua família de origem.

O título em alemão, Das lied in mir (A canção em mim), dá ênfase ao fato de que a música estava presente no psiquismo de Maria, sem que ela própria tivesse consciência. A presença e a ausência da música em Maria possibilitam um retorno ao percurso utilizado por Freud na construção de sua metapsicologia. Segundo Freud (1915b), uma lembrança latente é um resíduo de um processo psíquico. Mas como se instauram, segundo Freud, no psiquismo, lembranças latentes que podem vir à consciência?

Dependendo da tradução que utilizamos para ler a obra freudiana, o termo Verdrängung assume um significado diferente. Em algumas traduções para o português utilizou-se a palavra 'repressão', em outras, verificou-se que o uso mais adequado seria 'recalque'. Pode-se entender as diferentes traduções como uma consequência da falta de clareza do próprio Freud no uso da palavra Verdrängung, bem como a própria riqueza da língua alemã. No início, os termos 'recalque' e 'defesa' foram utilizados como quase equivalentes.

No Dicionário Comentado do Alemão de Freud, Hanns (1996) afirma que o termo em alemão é traduzido por 'recalque' ou 'repressão'. "O verbo verdrängen genericamente significa "empurrar para o lado", "desalojar" (...) Conotativamente, verdrängen remete a uma sensação de "sufoco", "incômodo", que leva o sujeito a desalojar o material que o incomoda." (p.355). O autor diferencia o uso de repressão e recalque em português. Aponta que a palavra recalque não é utilizada coloquialmente e abarca

um sentido originário da linguagem da construção (rebaixamento da terra ou de paredes após a construção). O radical "calcar" tem diversos usos (calcar a terra, o terreno=pressionar-pisar-apertar). 
Também se aplica, em linguagem mais figurada, a idéia de oprimir, vexar, desprezar etc. (Hanns, 1996, p. 358).

As primeiras traduções da obra freudiana foram feitas do inglês para o português. Houve um uso indiscriminado das palavras repressão e recalcamento para traduzir Verdrängung. As traduções mais recentes, feitas diretamente do alemão, nos possibilitam uma melhor apreensão das ideias de Freud, no que se refere à fundação do aparelho psíquico freudiano. Nos artigos O Recalque (Freud, 1915a/ 2004) e Inconsciente (1915b/2004), traduzidos por Luiz A. Hanns, Verdrängung é traduzido pelas palavras recalcamento/recalcamento originário e repressão, bem como termos derivados destas palavras.

$\mathrm{Na}$ primeira tópica freudiana, "o aparelho psíquico é concebido como um instrumento formado por um conjunto de elementos denominados instâncias ou sistemas. (...) os sistemas se dispõem numa sequência, de tal modo que sejam percorridos pela excitação segundo uma determinada série." (Garcia-Roza, 1996, p. 157-158). O mesmo autor salienta que Freud não utilizou os dois termos como sinônimos. O termo instância é utilizado, por exemplo, quando Freud fala sobre censura. Sistema já é utilizado quando escreve sobre retenção dos traços ou da percepção; exemplo sistema perceptivo. (Garcia-Roza, 1996, p.157-158).

As percepções (Wahrnemungen), que em si mesmas não constituem memória, vão dar lugar as primeiras inscrições (Niedershriften) que passam a funcionar como signos de percepção (Wahrnehmungszeichen). Estes signos de percepção formam o primeiro registro mnêmico, ainda não estruturado como linguagem, mas organizado de acordo com a associação por simultaneidade. 0 registro seguinte destes signos é o da inconsciência (Unbewusstsein), onde eles serão organizados não mais segundo a associação por simultaneidade, mas segundo a associação por causalidade. 0 terceiro registro é da pré-consciência (Vorbewusstsein) onde essas representações-objeto se ligam as representações-palavra. Este último registro é o único capaz de acesso à consciência. (GarciaRoza, 1996, p. 162)

Para se referir às primeiras marcas, às experiências arcaicas muito fortes, às primeiras diferenciações que instauram o inconsciente e que jamais chegarão à consciência, Freud nomeou Verdrängung. Luiz A. Hanns optou por traduzir Verdrängung por recalque originário, justamente para passar o sentido que a palavra recalque pode assumir em português de construção. Neste sentido, entende-se que de fato esta é a melhor tradução para Verdrängung, já que abarca o sentido de origem do aparelho psíquico.

As primeiras percepções recalcadas darão origem ao aparelho psíquico que, a partir de então, não cessará de funcionar. Segundo Garcia-Roza (1996, p.155), 
Freud concebe o aparelho psíquico que se constitui "enquanto aparelho de memória e de linguagem."

O inconsciente, regido pelo princípio do prazer, opera segundo o processo primário e tem uma abrangência maior que o recalcado. Entende-se que os conteúdos do inconsciente são "representantes" das pulsões e procuram constantemente retornar à consciência. Há uma energia que circula livremente no inconsciente. A representação inconsciente é apenas a representação de coisa.

No pré-consciente, a energia está ligada por meio de cadeias associativas e pode tanto se ligar aos conteúdos inconscientes, por meio dos pensamentos oníricos, como a consciência, através dos devaneios diurnos. Na passagem dos conteúdos ICS para PCS, há uma primeira censura. Os conteúdos só passarão de um sistema ao outro por meio de condensações e deslocamentos. Posteriormente, há uma segunda censura que dificulta também a passagem de conteúdos do PCS para o Cs. "A representação consciente engloba a representação de coisa mais a representação de palavra correspondente." (Laplanche \& Pontalis, 1988, p.583).

Freud (1915b, p.31) afirma que "no processo de recalque o afeto se separa de sua ideia e ambos seguem seus destinos separadamente." Referindo-se à dinâmica do recalque, Freud afirma que o recalque é "um processo que ocorre na fronteira entre os sistemas ICS e PCS (Cs) e que ele opera sobre as ideias [Vorstellung] que aí se encontram. Afirma que o Ics tem muita vitalidade e é capaz de influenciar o PCS e, ao mesmo tempo, de ser influenciado por ele." (Freud, 1915b/2004, p.40).

Segundo Laplanche e Pontalis, (1988, p.595), a repressão é um mecanismo consciente que atua ao nível da segunda censura. Segundo os autores, Freud situa a repressão entre o consciente e o pré-consciente. Trata-se da exclusão de algum material do campo da consciência. As motivações morais desempenham um papel predominante na repressão.

Retornando ao filme... Maria recalcou a história de sua família de origem. Ao ouvir a música, a percepção sonora da melodia toma conta dela e, ao cantála, Maria é tomada por um afeto desconcertante, cindido de uma representação. Como o tempo no inconsciente não é cronológico, é algo vivo; o afeto, que fora recalcado por Maria, é atualizado no momento em que ela ouve a música, passando, assim, a ser algo presente e intenso em sua consciência. 
O pai adotivo conta, no filme, que a música era uma canção que fora cantada por sua mãe adotiva. Ao assistir ao filme, é possível imaginar se esta canção também não era cantada pela mãe de biológica de Maria. A hipótese levantada deve-se ao fato de Maria ter ficado muito mobilizada no aeroporto, quando escutou e cantou a canção. Além disso, esta música é típica na Argentina e as mães, em geral, cantam para embalar seus filhos. Se tal hipótese tem fundamento, possivelmente, a música assumiu o valor de objeto transicional, quando Maria foi "adotada". A letra da música é apresentada para justificar tal suposição:

\author{
ARRORRÓ2 MI NIÑO \\ Arrorró mi niño \\ arrorró mi amor \\ arrorró pedazo de mi corazón \\ este niño lindo \\ que nació de día \\ quiere que lo lleve a la dulcería \\ este niño lindo \\ que nació de noche \\ quiere que lo lleve a pasear en coche \\ Duérme te mi niño \\ duérme te pedazo de mi corazón
}

Segundo Winnicott (1951/1975), o objeto transicional introduz uma experiência intermediária, na qual possibilita "a capacidade do bebê criar, imaginar, inventar, originar, produzir um objeto" (Winnicott, 1951/1975, p. 14). A experiência intermediária acontece a partir daquilo que é experimentado e introjetado na relação mãe/bebê. O bebê projeta no objeto a relação verdadeira de objeto vivida anteriormente com sua mãe. No filme, a música assumiu o sentido de um fenômeno transicional: a melodia ocupou o campo do intermediário, algo que ligava e estabelecia um laço psíquico entre as "duas" mães. Intuitivamente, a mãe adotiva, nesta passagem da maternidade, conserva a canção que a mãe biológica embalava seu bebê, o que possibilitou a Maria a inserção e a adaptação nesta nova família. Entretanto, se, em um primeiro momento a música assumiu uma importância na vida de Maria, com o passar do tempo, tornou-se um corpo encapsulado no ego, uma lembrança que deveria ser esquecida e recalcada.

A ilusão de que nascera de seus pais adotivos veio do próprio processo de repressão vivido pela sua família adotiva. A "nova" mãe contou, para Maria,

\footnotetext{
${ }^{2}$ Arroró é uma onomatopéia.
} 
histórias sobre sua gravidez e sobre como ela era em bebê. Criou-se um mito familiar que dizia respeito à origem do grupo familiar. Houve um processo de negação grupal, enquanto um mecanismo de defesa do grupo familiar. O mito familiar foi fundado na negação do que de fato havia ocorrido e teve a função de evitar a dor psíquica.

A negatividade na linguagem cotidiana, como salienta Kaës (2003), é usada com uma conotação pejorativa, aquilo que falta, mas em Freud a negatividade apresenta "uma consistência psíquica desprovida de julgamento de valor". ( $p$. 21).

O debate sobre o negativo que se iniciou desde Freud $(1905,1925)$ e que continua sendo objeto de estudo de autores contemporâneos acaba enriquecendo a compreensão do funcionamento psíquico do sujeito. Não é o intuito, deste trabalho, ampliar a discussão sobre as vicissitudes que os diversos autores trazem a respeito da figura do negativo. Entretanto, as ideias de André Green a respeito do negativo contribuem para o entendimento do conceito dentro da psicanálise e, por essa razão, é apresentado alguns aspectos destacados por esse autor.

André Green aponta:

Há muitos anos, eu propus que designássemos, sob a denominação de trabalho do negativo, o conjunto das operações psíquicas para as quais o recalque é o protótipo, tendo dado posteriormente variantes distintas: tais como a negação, a condenação ("desaveu"), o repúdio ("forclusão"). (Green, 1988, p.24).

Nesse mesmo texto, Green (1988a) prossegue, dizendo que o trabalho do negativo não se restringe ao Ego e a seus mecanismos de defesa, mas às outras instâncias do aparelho psíquico, Id e Superego.

Green (1995, 2008), ao abordar as vicissitudes do trabalho do negativo, retoma a discussão a respeito da alucinação negativa. Numa tentativa de definir a expressão, esse autor coloca que "alucinação negativa é a não-percepção de um objeto ou de um fenômeno psíquico perceptível. Trata-se então de um fenômeno de apagamento daquilo que deveria ser percebido." (Green, 2008, p.267; grifo de Green).

Valendo-se das ideias de Freud ${ }^{3}$ sobre os esquecimentos, os "brancos" que aparecem no decurso do pensamento do indivíduo, Green (2008) vislumbra a

\footnotetext{
${ }^{3}$ No artigo Gradiva, Freud apresenta o conceito alucinação negativa. (Freud, 1907 [1906], p.71)
} 
origem da produção alucinatória. Esta resultaria de uma dupla ação a partir de uma interface:

- sobre sua face externa; uma percepção indesejável, insuportável, ou intolerável agrega uma alucinação negativa que traduz o desejo de recusá-la ao ponto de negar a existência dos objetos da percepção.

- sobre sua face interna; uma representação inconsciente de desejo (abolida) procura se tornar consciente mas está impedida de fazê-lo pela barreira do sistema percepção-consciência. (Green, 2008, p.268).

Mais adiante, no mesmo texto, Green (2008) conclui que, apesar de Freud não explicitar claramente, a alucinação negativa "desempenha um papel essencial no conceito de recalcamento da realidade, que é bastante difícil de conceber." (p.268).

Green (2008) aponta a questão da alucinação negativa enquanto um fenômeno de apagamento, essa não percepção de algo que deveria ser percebido. No filme há duas cenas que permitem pensar sobre este processo: a primeira cena é quando Maria pergunta a seu pai sobre o Topo Gigio que comprara em Buenos Aires, já que the parecia tão conhecido. Seu pai responde que não se lembra se ela teve um brinquedo como aquele. Em outra cena, Maria, após descobrir que seus tios biológicos estiveram na casa de seus pais adotivos para saber se eles sabiam do paradeiro de Maria, questiona seu pai sobre o ocorrido. O pai questiona a veracidade da informação, dizendo que não se lembra, justificando que sua tia poderia estar mentindo. Esses brancos e apagamentos acabam assumindo a função psíquica de um mecanismo de defesa do ego que impossibilita que venha à consciência o conteúdo que foi reprimido.

Apesar de a família negar o sequestro e se utilizar do mecanismo de alucinação negativa, com o intuito de camuflar seus atos, o conteúdo reprimido vem à tona. Freud (1912-1913, p. 188) já afirmava a existência de processos psíquicos que avançam de uma geração à outra. Mesmo havendo conteúdos reprimidos, restam ainda vestígios.

podemos presumir com segurança que nenhuma geração pode ocultar, à geração a que sucede, nada de seus processos mentais mais importantes, pois a psicanálise nos mostrou que todos possuem, na atividade mental inconsciente, um apparatus que os capacita a interpretar as reações de outras pessoas, isto é, a desfazer as deformações que os outros impuseram à expressão de seus próprios sentimentos. Uma tal compreensão inconsciente de todos os costumes, cerimônias e dogmas que restaram da relação original com 
- pai pode ter possibilitado às gerações posteriores receberem sua herança de emoção. (Freud, 1912-1913, p. 188).

A ideia apresentada por Freud, que uma geração não consegue esconder das demais os seus processos mentais, coloca-nos frente à questão das heranças psíquicas recebidas de nossas famílias e da sociedade. Há famílias que mantêm alianças inconscientes e pactos da ordem dos segredos. Segundo Freud (1907 [1906], p.55), "As ideias só são reprimidas porque estão associadas à liberação de sentimentos que devem ser evitados."

Rosa (2001) discute que muitas vezes aquele conteúdo que os pais temem que seja transmitido a seus filhos é justamente o que é passado e retorna na forma de sintoma: "a transmissão opera-se à sua revelia, dado que o não-dito comparece na subjetividade da criança através dos processos de identificação e construção de valores e ideais, na trajetória edipiana." (p. 127). Não é possível dizer que houve o surgimento de sintomas no grupo familiar, devido ao material psíquico reprimido, pois o filme não aborda o assunto.

A questão que se coloca é: por que motivo Maria resolve romper com aliança familiar inconsciente de manter o segredo em relação a sua origem? 0 que foi mobilizado em Maria para que ela investigasse o passado? Uma explicação possível pode ser encontrada no texto de Freud, Romances Familiares (1909). Ao escrever sobre a relação criança e seus pais, Freud (1909, p. 243) discorre sobre o fato que, para a criança pequena, os pais são a fonte de todo o conhecimento. "O desejo mais intenso e mais importante da criança nesses primeiros anos é igualar-se aos pais (...). Contudo, ao desenvolver-se intelectualmente, a criança acaba por descobrir gradualmente a categoria que a que seus pais pertencem."

Maria, mobilizada pelo afeto desencadeado pela música, desvenda sua história familiar, apropriando-se conscientemente dos fatos recalcados em seu inconsciente. Em uma cena, mobilizada por tudo que havia descoberto, Maria insinua-se para seu pai, provocando-o sexualmente. Nesta cena, Maria provoca o pai, como se estivesse desafiando-o para ver até onde ia o desejo dele por ela. Entretanto, o pai consegue conter a filha, evitando que ela concretizassse suas fantasias edípicas inconscientes. É possível pensar também o quanto Maria estava tomada por conteúdos que não conseguia elaborar e administrar, já que invadiram seu psiquismo como uma avalanche. 
Aos poucos, Maria consegue montar o quebra-cabeça de sua história e seus tios solicitam que ela denuncie seu pai adotivo, pois ele deve responder pelo que fez. Maria não consegue acatar o pedido de formar uma aliança com a família de origem, pois ele era seu "pai". Seus tios tentam persuadi-la, já que seu verdadeiro pai não é ele, mas Maria não consegue denunciá-lo. O filme não se aprofunda nas questões que a levam a tomar tal decisão, mas é possível pensar que a atitude de Maria deve-se ao vínculo que teve com seu pai. A película termina com o pai de Maria voltando para a Alemanha e ela, caminhando pelas ruas de Buenos Aires.

\section{CONSIDERAÇÕES FINAIS}

O presente trabalho buscou discutir e diferenciar os conceitos freudianos: recalque e repressão. Tal discussão se faz pertinente, pois algumas traduções da obra de Freud, bem como trabalhos publicados, têm utilizado os dois termos como sinônimos. Foi utilizado o filme "O dia em que eu não nasci" como um recurso ilustrativo de tais conceitos.

A história narrada no filme é, possivelmente, a história de muitas crianças que foram separadas de seus pais. A película é feita em um momento histórico em que os argentinos, após anos de repressão social, podem resgatar e falar sobre a própria história e aquilo que foi, por anos, ocultado e negado.

No filme, algumas partes da história de Maria Ihe foram sonegadas. Houve tentativas de tapar as lacunas vivenciadas, mas o afeto recalcado veio à tona assim que Maria viu-se frente a um fragmento de sua história passada. Como foi dito anteriormente, a representação recalcada teve acesso à consciência. Entretanto, este fragmento de representação veio à consciência de Maria sem o seu significante. Desse modo, ela se mune pelo desejo epistemológico de entender o significado mais profundo daquela música. Por muito tempo, ela não pôde desvendar o segredo familiar, pois era da ordem de muito sofrimento psíquico: seus pais adotivos a sequestraram! Nesse sentido, talvez a opção que Ihe restava era o recalcamento. Entretanto, quando escuta a música e decide pensar sobre a mesma, não nega a realidade e opta por descobrir a própria história, já que encontra, em si, recursos para enfrentar e desvendar os segredos familiares.

Em Totem e Tabu, Freud (1912-1913/1980, p.188) cita a célebre frase de Goethe: "Aquilo que herdaste de teus pais, conquista-o para fazê-lo teu." Como 
foi exposto anteriormente, os conteúdos que foram ocultados por uma geração, manifestar-se-ão nas gerações seguintes. Então, cabe a cada um apropriar-se e dar sentido àquilo que se herdou.

\section{REFERÊNCIAS}

Freud, S. (1907[1906]/1980). Delírios e Sonhos de Gradiva de Jensen. In S. Freud, Edição standard brasileira das obras psicológicas completas de Sigmund Freud. Vol. IX: Gradiva de Jensen e outros trabalhos (pp. 13-98). Rio de Janeiro: Imago. (Trabalho original publicado em 1907).

Freud, S. (1909/1980). Romances Familiares. In S. Freud, Edição standard brasileira das obras psicológicas completas de Sigmund Freud. Vol. IX: Gradiva de Jensen e outros trabalhos (pp. 243-247). Rio de Janeiro: Imago. (Trabalho original publicado em 1907).

Freud, S. (1912-1913/1980). Totem e tabu. In S. Freud, Edição standard brasileira das obras psicológicas completas de Sigmund Freud. Vol. XIII: Totem e tabu e outros trabalhos (pp. 13-197). Rio de Janeiro: Imago. (Trabalho original publicado em 1913).

Freud, S. (1915a/2004). O Recalque. In S. Freud, Obras Psicológicas de Sigmund Freud, Vol. 1: Escritos sobre a Psicologia do Inconsciente (pp. 175-193). Rio de Janeiro: Imago. (Trabalho original publicado em 1915).

Freud, S. (1915b/2004). O Inconsciente. In S. Freud, Obras Psicológicas de Sigmund Freud, Vol. 2: Escritos sobre a Psicologia do Inconsciente (pp. 1374). Rio de Janeiro: Imago. (Trabalho original publicado em 1915).

Freud, S. (1925/1980). A Negativa. In S. Freud, Edição standard brasileira das obras psicológicas completas de Sigmund Freud. Vol. XIX: O Ego e o id e outros trabalhos (pp. 293-300). Rio de Janeiro: Imago. (Trabalho original publicado em 1925).

Garcia-Roza, L. A. (1996). Introdução à Metapsicologia Freudiana 2. Rio de Janeiro: Jorge Zahar.

Green, A. (1988). O trabalho do negativo. Ide, 16, 24-28.

Green, A. (1995). El trabajo de lo negativo. Buenos Aires: Amorrortu.

Green, A. (2008). Orientações para uma psicanálise contemporânea. São Paulo: Imago.

Hanns, L. A. (1996). Dicionário comentado do alemão de Freud. São Paulo: Imago. 
Kaës, R. (2003). A negatividade: problemática geral. Psicologia USP, 14(1), 2136.

Laplanche, J. \& Pontalis, J. B. (1988). Vocabulário de psicanálise. São Paulo: Martins Fontes.

Rosa, M. D. (2001). O não-dito familiar e a transmissão da história. Psyché, 5(8), 123-137.

Winnicott, D. W. (1951/1975). Objetos Transicionais e Fenômenos Transicionais. In D. W. Winnicott, O brincar \& a Realidade (pp. 13-44). Rio de Janeiro: Imago. (Trabalho original publicado em 1951).

Contato: mlupaiva@usp.br

Recebido em: 18/10/2011

Revisado em: 15/11/2011

Aceito em: 01/12/2011 